\title{
Arbitragem no Setor Público: apelo do interesse público e desafios
}

\author{
Arbitration in the public sector: the public interest appeal and challenges
}

Albert Medeiros Karl ${ }^{1}$

\section{RESUMO}

O presente artigo analisa o percurso histórico da sociedade brasileira sob o foco da gestão de sua administração pública. Para tanto, é traçado um perfil histórico com características da evolução de uma administração burocrática a uma administração publicista com prisma gerencial. Em seguida, é narrado um breve histórico do sistema arbitral para, posteriormente, serem abordados aspectos normativos e doutrinários que permeiam a aplicação da arbitragem ao setor público. Finalmente, é analisada a instituição da convenção da arbitragem na administração pública brasileira como um grande passo para o desenvolvimento econômico e social do país.

Palavras-chave: Arbitragem; Administração Pública; Gestão gerencial; Justiça arbitral.

\section{ABSTRACT}

This article analyzes the historical path of Brazilian society from the perspective of the management of its public administration. To this end, a historical profile is drawn with characteristics of the evolution from a bureaucratic administration to a publicist administration with a managerial perspective. Then, a brief history of the arbitral system is narrated so that, later, normative, and doctrinal aspects that permeate the application of arbitration to the public sector are addressed. Finally, the institution of the arbitration convention in the Brazilian public administration is analyzed as a major step towards the country's economic and social development.

Keywords: Arbitration; Public Administration; Managerial organization; Arbitral justice.

\footnotetext{
${ }^{1}$ Especialista em Direito Administrativo e Gestão Pública pela Universidade Potiguar - UnP. Mestrando em Direito e Políticas Públicas pela Atenas College University. E-mail: albertmkarl@gmail.com
} 


\section{Introdução}

A Administração Pública brasileira, hodiernamente, deve assumir um papel mais desenvolvimentista na sociedade, abandonando o modelo de administração anterior que era puramente hierarquizado, rígido e impessoal, para abarcar um modelo mais flexível, visando a uma gestão pública eminentemente gerencial com foco nos resultados.

Para tanto, diversas mudanças pró-ativas já foram implementadas, principalmente na seara legislativa, em que diversas normas legais e infralegais e emendas constitucionais foram aprovadas para promover justamente essa mudança de perfil autoritário de Estado.

Dentre essas alterações no arcabouço normativo, destaca-se a festejada Emenda Constitucional n. 45, aprovada em 30 de dezembro de 2004, na tentativa, como norma programática, de fornecer um verdadeiro comando aos legisladores, juristas e gestores públicos, para impulsionar o Estado à efetivação de uma intensiva reforma no atual paradigma da administração brasileira, visando à persecução incessante do princípio da eficiência.

Há décadas a máxima efetivação do interesse público é restringida pela insuficiência de normatização que permita ao Poder Público equiparar-se às modernas práticas empresariais de gestão, prejudicando sobremaneira um adequado e célere atendimento dos anseios da coletividade, especialmente nos serviços públicos.
$\mathrm{Na}$ área privada, a intensidade das relações negociais permitiu que se seguisse outro rumo, culminando com a edição da lei n. 9.307 em 1996, a qual permitiu que, oportunamente, empresários pudessem escolher submeter seus conflitos comerciais a câmaras de arbitragem, privadas, evitando que a morosidade dos processos no Poder Judiciário prejudicasse o regular andamento dos negócios e, consequentemente, o desenvolvimento econômico e social do Brasil.

A finalidade, portanto, do presente trabalho, é demonstrar a imprescindibilidade da adequação do Estado brasileiro a práticas mais modernas de gestão da coisa pública, sobretudo com a implementação de técnicas já amplamente utilizadas no meio empresarial na administração pública, em especial, a instituição da arbitragem no setor público.

\section{Transição do modelo burocrático para a administração pública gerencial no Brasil}

\section{Evolução histórica, características $e$ diferenças entre o velho $e$ novo modelo gerencial de administração}

A humanidade, desde a sua origem, passou por diversas mudanças na sua história, como consequência de diversos acontecimentos culturais, sociais, políticos, científicos, mercadológicos etc.

Como repercussão, a sociedade se desenvolveu como um todo, abandonando formas primitivas de relações sociais e de trabalho para inter- 
relacionar-se de forma mais complexa, como a divisão de territórios prédefinidos e populações com origens comuns em Estados, unificados por um governo central, a quem fora dada certa parcela de poder sobre os indivíduos que ali habitavam.

Nesse sentido, as sociedades modernas foram formando nações, independentes entre si, com governos que passaram a assumir certas funções predominantemente públicas. Primariamente, essas funções eram a de proteger os indivíduos de ameaças externas e garantir liberdades básicas aos cidadãos, como a de possuir bens $\mathrm{e}$ amealhar escravos.

Em um contexto mais contemporâneo à realidade atual, o Estado passou a gerir funções públicas essenciais, como a profusão do ensino, a oferta de tratamentos de saúde à população e a manutenção de órgãos de segurança pública.

Assim, os governos passaram de meros espectadores das atividades coletivas para legítimos regulamentadores e participantes de diversas relações sociais, comerciais, burocráticas, notariais, trabalhistas, tributárias entre outras, ou seja, o Estado, ultrapassando o modelo liberal - em que a sociedade era deixada livre para desenvolver-se -, passou de coadjuvante a ator da realidade social, para ocupar diversos espaços públicos antes deixados exclusivamente ao arbítrio da iniciativa dos particulares.

Haja vista o Estado ter abarcado diversas atividades essenciais à manutenção e prosperidade da sociedade, ele teve de especializar-se em diversos ramos de atuação: segurança pública, ensino, saúde pública, previdência social, Poder Judiciário, bens e propriedades, relações familiares, relações diplomáticas, entre diversos outros. Sucintamente, daí surgiu a ideia de administração pública, de uma gestão por um governo hierarquizado de diversas áreas da vida humana.

No Brasil, já analisando por amostragem o século XX, a administração pública restou marcadamente burocrática e hierarquizada, extremamente centralizada, direcionando sua linha de ação nos meios - procedimentos e processos - colocados à disposição da administração, e não com foco nos resultados, para consecução do interesse público.

Esse modelo de governo gerou diversas crises institucionais, culminando na migração para um novo modelo de administração com fulcro gerencial, que se aproxima muito da doutrina utilizada na área empresarial, que foca primordialmente nos resultados, ou seja, de atendimento aos interesses da coletividade e prestação eficiente dos serviços públicos.

Esse novo modelo abrange a utilização, de forma mais intensa e eficaz possível, de princípios basilares da administração pública, como a economicidade, continuidade, especialidade e eficiência, sem abster-se, contudo, da probidade, impessoalidade, moralidade, legalidade, razoabilidade e segurança jurídica na condução da res publica.

Portanto, esse incipiente modelo de administração, melhor dizendo, gerenciamento, pauta-se na profissionalização/especialização dos servidores públicos, foco primordial nos re- 
sultados em detrimento dos métodos e processos utilizados, atingimento das finalidades públicas, descentralização de atividades governamentais por áreas específicas de atuação e participação democrática da população na escolha e condução das políticas públicas.

\section{A nova administração brasileira com foco negocial}

Historicamente, a administração pública brasileira sempre restou atrasada em relação às práticas comerciais, em qualquer época em que cotejadas.

A força do poder econômico na história mundial, recrudescida ainda mais com o advento e império do capitalismo, sempre constitui-se numa gigante e implacável força motora em diversas áreas da sociedade, como a trabalhista, de desenvolvimento tecnológico, científica, social, publicitária, filosófica, econômica, de comércio exterior, entre diversas outras - inclusive ameaçando a estabilidade de diversos governos -, experimentaram, ao longo do tempo, vigorosas mudanças conjunturais, que modificaram, por conseguinte, a sociedade como um todo.

Então, mostrou-se necessário, para atender de forma imediata ao irrefreável fluxo de capitais, por vezes multinacional, à expansão econômica e à infindável perseguição do lucro, as práticas comerciais sempre necessitaram ser prontamente atendidas, serem dotadas de enorme flexibilidade e receberem suporte de constantes inovações tecnológicas.
Inversamente, a administração pública sempre demonstrou um avanço mais lento e gradual em relação à área privada. Comumente, eram necessários diversos anos ou décadas para que o Poder Público alcançasse similares métodos e tecnologias abarcados pelas empresas tempos atrás, estando estas já em novo e avançado nível de evolução, permanecendo aquela sempre defasada em relação a estas.

Em grande parte, isso deveu-se à imensa burocratização e legalismo em que é lastrada a atuação estatal. A formalidade dos procedimentos públicos e a exigibilidade de licitação em diversas (e por vezes longas) etapas para consumar-se prejudica demasiadamente a celeridade dos processos. Soma-se a isso à mora legislativa que, para aprovar novas leis modernizantes, exige, via de regra, a apresentação, o trânsito pelas Casas Legislativas e a discussão do projeto de lei, além da sanção ou veto do Presidente da República e publicação em diário oficial para passar a viger.

Ainda quanto ao Poder Legislativo, em muitas matérias dependentes de normatização, ele queda-se inerte em relação a diversas necessidades sociais. A sociedade não para; está em constante evolução. Praticamente todo dia a sociedade possui um novo anseio, todos os dias surgem novas e inusitadas necessidades e de fato as leis não conseguem acompanhar tamanha mudança quotidiana ou sequer esgotar em determinadas leis todas as possibilidades sociais existentes e futuras.

Partindo dessa premissa, o Congresso Nacional está sempre a um 
passo atrás da coletividade. Com isso, uma série de direitos, dependentes de regulamentação, são inviabilizados pela inércia ou mora legislativa, prejudicando o desenvolvimento econômico e social brasileiros, pois é dado ao particular exercer tudo o que a lei não veda, mas à administração é permitido fazer apenas o que a lei expressamente autoriza.

Mais acentuadamente desde o fim do século passado, o Poder Público brasileiro, em suas diversas vertentes - Poderes Executivo, Legislativo e Judiciário - vêm assumindo esse desafio institucional, o de modernizar continuamente a administração pública brasileira, para que atinja patamares toleráveis de eficiência na gestão da coisa pública e diversas outras necessidades da coletividade, como garantia maior do princípio e fundamento da República Federativa do Brasil, a dignidade da pessoa humana.

A grande força motriz para esse desenvolvimento é flexibilizar o direito público, promovendo inovações legislativas que o permeiem de disposições particularmente do direito privado, a fim de desembaraçar diversos procedimentos públicos severamente morosos, para dar lugar a um mecanismo célere, em que são priorizadas de forma maioral as finalidades das instituições públicas, sem obviamente olvidar-se dos mecanismos que perfazem o nosso Estado Democrática de Direito, cuja base é a legalidade, impessoalidade e moralidade na administração pública.

Nesse diapasão, o grande foco atual da administração pública é aproximar-se da modernidade e efetividade das práticas do meio empresarial, a fim de alinhar-se às tendências mundiais de gerenciamento e controle por resultados, pois se está lidando não com a perspectiva de lucro ou expansão econômica, mas com a verdadeira satisfação das necessidades e aspirações da coletividade, por uma prestação célere e eficiente dos serviços públicos, atendendo de forma universal às demandas da sociedade.

\section{Aspectos legais e constitucionais para utilização da arbitragem no setor público}

\section{Breve histórico do sistema arbitral}

A lei que regulamentou os institutos do compromisso arbitral e da cláusula compromissória, ambas espécies do gênero convenção de arbitragem, foi promulgada apenas em 23 de setembro de 1996 por intermédio da lei n. 9.307.

Essa lei foi fruto de diversos apelos por parte da sociedade há tempos e, principalmente, do meio empresarial. A sociedade já vinha sentindo fortemente o peso da morosidade do Poder Judiciário, onde inúmeros processos acumulavam-se e vários conflitos restavam-se sem solução por muitos anos, ou mesmo décadas.

A vertente que sofria bastante nesse contexto era a classe empresarial. Ávida por celeridade em suas práticas comerciais, quando surgiam conflitos nas relações de negócios e não se chegava a um consenso, fatidicamente o processo seria submetido ao Poder Judiciário, quando intensifica-se a agonia, pela certeza quase absoluta de 
que aquela demanda iria perdurar longos anos até sua solução, seja pela impossibilidade de absorver a intensa carga de processos instaurados ou aos inúmeros recursos processuais disponíveis às partes, que prolongavam a sentença final.

Embora implementada tardiamente no Brasil, e pesando o fato de já ter sido implementada por vários outros países há muitos anos, a referida lei foi recebida com bastante ovação e rapidamente foi posta em prática por diversos grupos empresariais, a fim de buscarem presteza na resolução dos seus impasses comerciais.

A justiça privada, como popularmente conhecida a arbitragem em alguns meios, é deveras uma espécie de jurisdição não estatal. O Poder Público autorizou essa forma alternativa de resolução de conflitos como alternativa legítima à fuga da jurisdição estatal, mais formal e, por consequência, mais lenta. É importante frisar que elas não disputam ou concorrem entre si, e que a instituição daquela não fere a Constituição Federal ou o Estado Democrático de Direito.

É relevante anotar também, quanto à denominação sentença arbitral, que antes do advento da lei $\mathrm{n}$. 9.307/96 os árbitros emitiam laudos arbitrais, e não sentenças, dividindo opiniões na doutrina e jurisprudência quanto à natureza e efeitos desse instituto.

Intensificava ainda mais o debate a característica de que tais decisões necessitavam de homologação judicial como requisito para sua eficácia, ou seja, tais decisões dos árbitros não eram definitivas; eram ineficientes por não promoverem a pacificação social desejada, a qual ocorria somente após a intervenção imperativa do Estado, através da homologação.

Impasses esses que foram dirimidos com a vigência da lei 9.307/96, restando pacificadas a doutrina e a jurisprudência divergentes quanto à sua natureza de provimentos judicial, sendo considerada desde então efetivamente uma sentença, e atestada a força de coisa julgada, pela sua característica de definitividade quanto ao direito posto e solucionado em seu juízo.

\section{Estudo normativo acerca da institui- ção da arbitragem}

Ela é mais comumente utilizada no campo dos negócios e pode ser pactuada através da previsão em um contrato específico - saliente-se que é independente deste - ou em simples acordo após o aparecimento da controvérsia, de serem submetidos, obrigatoriamente, à justiça arbitral.

A primeira modalidade citada acima - previsão da convenção de arbitragem em contrato específico ou anexo a ele e frise-se, autônomo- é denominada cláusula compromissória; após estabelecida a contenda, em comum acordo das partes, ela é encetada pelo instituto nominado compromisso arbitral. Nesta monta, verifica-se que sua natureza é inegavelmente contratual.

A convenção de arbitragem, após sua pactuação, é obrigatória, ou seja, não pode o contratante alegar que não deseja mais utilizar-se deste âmbito e recorrer ao Judiciário estatal para a solução de pontual controvérsia, a 
não ser que concorram vícios ou nulidades na sua constituição.

Outro aspecto importante é que, assim como na justiça estatal, a sentença arbitral tem força de título executivo judicial e faz coisa julgada, um dos mais importantes fenômenos de perpetuidade da sentença judicial, independendo, portanto, de homologação judicial.

Dispõe, corroborando os argumentos apresentados, o Código de Processo Civil Brasileiro (lei n. 5.869/73) em seu art. 86 que:

Art. 86. As causas cíveis serão processadas e decididas, ou simplesmente decididas, pelos órgãos jurisdicionais, nos limites de sua competência, ressalvada às partes a faculdade de instituírem juízo arbitral. (grifo nosso)

Ainda orientado pelo mesmo diploma normativo, disciplina o seu art. 267, art. VII, que a convenção pretérita da arbitragem autoriza o juiz, inclusive, a extinguir o processo sem resolução de mérito.

Ainda em caso de apresentação de petição de contestação pelo réu, se for alegada convenção de arbitragem, ela deverá ser primeiramente enfrentada na peça, antes da alegação dos fundamentos de fato e de direito do mérito, conforme o art. 301, IX, do digesto processual civil.

Interessante notar, nesse último artigo citado, no seu par. $4^{\circ}$, que não é lícito ao juiz conhecer de ofício da convenção, ou seja, ele só poderá analisá-la se arguida por qualquer das partes. Essa disposição reforça o princípio da inafastabilidade da jurisdição previsto no art. $5^{\circ}, \mathrm{XXXV}$, da Consti- tuição Brasileira de 1988, segundo a qual "a lei não excluirá da apreciação do Poder Judiciário lesão ou ameaça de lesão a direito", pois, mesmo se as partes instituíram previamente a arbitragem para resolução de seus conflitos, mas quiserem, sem oposição do outro, que sua questão seja submetida ao crivo do Poder Judiciário, eles poderão silenciar quanto ao pactuado, em juízo, e seguirem com seu conflito para apreciação e definição pela própria jurisdição do Estado.

Um ponto de retenção a sua abrangência é quanto à execução das sentenças arbitrais. O juízo arbitral não tem competência para executar suas próprias decisões, por limitação voluntária do legislador, devendo submetêlas ao Poder Judiciário.

A partir daí segue disciplinamento próprio da legislação processual civil, seguindo procedimento autônomo, inclusive com previsão de liquidação de sentença, se a decisão arbitral foi ilíquida, fase de cumprimento de sentença e expedição de mandado de penhora e avaliação e embargos do devedor, se for o caso.

\section{Arbitragem: importante passo para o desenvolvimento econômico e social do país}

No atual contexto do Brasil, é fato que a burocratização estatal e a inflexibilidade de diversos de seus procedimentos prejudicam muito o avanço do país tanto em seu aspecto de democracia e cidadania quanto em seu desenvolvimento econômico.

Urge, então, que o Estado, flexibilizando e adaptando os trâmites de 
suas demandas, obviamente acompanhado de uma legislação moderna e autorizativa, amolde-se de forma mais rápida aos anseios da sociedade, visando a atender prontamente as insurgentes necessidades públicas.

Uma forma eficaz de promover e acompanhar essas mutações sociais é através da utilização, por parte do Estado, de técnicas mais competitivas e modernas, similares às adotadas nas relações empresariais.

Permanecendo nesse panorama, o Estado oferta inúmeros serviços públicos, que vão desde simples matrículas em instituições de ensino fundamental a operações militares internacionais de ajuda humanitária, fora atividades do nosso cotidiano, como licenças para construção de casas, permissão para dirigir veículo automotor, os órgãos de segurança pública como as polícias militares estaduais, etc.

Em última análise, todos os órgãos públicos, sejam eles do Poder Executivo, Legislativo ou Judiciário, por expressa previsão legal, compram e contratam serviços e produtos em geral por meio de licitação.

O procedimento licitatório é, muitas vezes, demorado, possuindo diversas fases a serem ultrapassadas até a adjudicação final do objeto ao vencedor do certame, tudo para garantir o atendimento a princípios caros a um Estado Democrático de Direito.

Os postulados da legalidade, isonomia, impessoalidade, moralidade, publicidade e probidade administrativa, expressos na Lei de Licitações (lei n. 8.666/93), para serem efetivamente cumpridos, necessitam de um procedimento liso, formal, em que deve haver uma estreita vinculação ao instrumento convocatório e proceder-se a um julgamento objetivo das propostas conforme as disposições do edital de concorrência pública.

Todo esse legalismo do procedimento concorrencial deve ser ausente de quaisquer vícios ou nulidades que possam vir a padecer tal processo de ilegalidade, causando prejuízos a direitos individuais dos concorrentes e transindividuais ou difusos, de toda a sociedade.

Fatalmente, toda essa excessiva legalidade, a burocracia procedimental e a orientação de atendimento a diversos requisitos legais e editalícios podem gerar certos vícios, impugnados por outros concorrentes ou reconhecidos, como dever, de ofício pela própria administração.

A celeuma já instaurada recrudesce quando o problema não se resolve na esfera administrativa, e fatidicamente o socorro ao Poder Judiciário mostra-se imprescindível.

O contratempo começa nesse momento. O Judiciário é cheio de nuances. Seu procedimento é deveras mais complexo que o processo licitatório; tem inúmeros prazos dilatórios e peremptórios, alegações de preliminares antes da análise do mérito, recursos processuais, competência jurisdicional, hierarquia e diferentes instâncias.

Ocorre que, na totalidade dos casos, tratando-se de Poder Público, as aquisições de bens e serviços são para atender necessidades públicas. E na jurisdição estatal, até a sentença se tornar definitiva com o seu trânsito em julgado, o embate não é resolvido e quem sofre é a população afetada. 
Agrava-se a situação quando as exigências da coletividade são as necessidades primárias, como saúde, saneamento básico, abastecimento de água, captação e tratamento de esgoto e lixo, entre outras, atividades estas consideradas essenciais à população, conforme o art. 10 da lei n. 7.783/93, possuindo, inclusive, restrições ao exercício do direito de greve pelos que atuam nessas áreas, haja vista a indispensabilidade e urgência de seus serviços para a sociedade como um todo.

Imagine a falta de certo medicamento na rede pública de saúde, a qual prejudica toda a assistência médica e hospitalar prestada aos necessitados, podendo, inclusive, ocasionar a perda do maior bem humano, a vida, devendo ela ser irrestritamente protegida pelo Estado.

Nesta monta, não deve o Estado, por questões procedimentais ou de mora do Poder Judiciário, retardar a assistência a um enfermo podendo levá-lo à morte, por não prestar um serviço ou medicamento pendente ainda de finalização da licitação para aquisição.

Transporte-se ainda o caso para o abastecimento de água e fornecimento de energia elétrica. Preveja como ficaria uma Delegacia de Polícia ou hospital sem "luz" ou um manicômio, creche ou juízo sem água por alguns dias; seria um verdadeiro caos, estorvando a vida de vários cidadãos e obstaculizando o funcionamento regular de vários serviços públicos relevantes.

Analisando a questão principiológica, o patrimônio, as finanças do Estado, não podem se sobrepujar a vida humana, sendo esta inegociável e devendo ser atendida em primeiro plano, como objetivo maior e fundamento da República Federativa Brasileira.

Ocorre que uma aquisição sem licitação, de forma direta, via de regra, padece de patente ilegalidade, é um grave vício que fere inclusive disposições expressas do texto constitucional.

Como lidar então com esta questão? A arbitragem seria um grande passo: flexibilizaria o rigor das normas legais, evitaria a delonga judiciária e ofereceria o bem da vida conflituoso com brevidade.

Portanto, a arbitragem é uma alternativa factível ao Estado, pois já regulamentada por lei e com sucesso nitidamente observável da área privada. É uma realidade em diversos outros países há muitas décadas, inclusive no setor público.

Falta ao Congresso Nacional, já ciente da necessidade social dessa providência, discutir e aprovar a utilização da arbitragem no setor público, obviamente promovendo alguns ajustes em relação à convenção arbitrada pelas empresas, visando atender a inexoráveis princípios democráticos da República, como a legalidade, impessoalidade e probidade, que devem ser sempre presentes na atuação da administração pública brasileira, como fator preponderante no desenvolvimento econômico e social do país.

\section{Considerações finais}

A flexibilidade, celeridade e racionalidade da convenção da arbitragem nas relações negociais é facilmente observada não só no Brasil, mas em diversos países do mundo. 
Seu sucesso é facilmente comprovado, especialmente pelos seus resultados, ao desembaraçar processos burocráticos que gerariam desnecessária demora ou evitar longos processos judiciais em caso de impasses contratuais, os quais perdurariam por anos ou mesmo décadas até solução.

Portanto, resta ao Brasil promover uma mudança generalizada e modernizante, implementada por todas as esferas de poder: um avanço jurisprudencial nas decisões do Poder Judiciário; uma mudança na forma de administração pelo Poder Executivo, com foco numa gestão racional e direcionada a resultados na sociedade; e, por fim, mas não menos importante, uma força-tarefa no Poder Legislativo, a fim de que sejam aprovadas inovações legislativas aptas a desenvolverem a administração pública brasileira.

Outro relevante papel é o que deve ser exercido pelos cidadãos. Cabe a todos acompanharem a execução das políticas públicas, se estão ocorrendo de forma a fomentar a economicidade e a transparência nas suas execuções, além de opinar para ditar os rumos da administração pública, através dos plebiscitos, referendos e audiências públicas realizadas, priorizando uma gestão pública efetiva e producente.

A adoção da arbitragem no setor público, portanto, é uma importante forma de alinhar tendências mercadológicas de êxito às rotinas da administração pública, modernizando-a, flexi- bilizando-a e modificando toda a burocracia então existente.

Assim, a finalidade precípua do Estado será cumprida, promovendo-se a cidadania ao seu maior patamar, através de uma prestação de serviços públicos em níveis excelentes, mormente os mais caros à sociedade, como as atividades essenciais à população, como saúde e segurança pública.

Não pode o Estado parar por entraves formalistas ou por impasses insolvíveis no Poder Judiciário, pois o bem maior, a vida humana, deve ser fielmente perseguido pelo Estado, sobretudo quando em detrimento da intangibilidade dos cofres públicos, por ser este postulado do patrimônio axiologicamente de menor estima em comparação com a vida e a dignidade da pessoa humana.

O novo paradigma mundial é o de uma administração pública que se apropriar cada vez mais do know-how aplicado pelas empresas neste novo milênio e transformar a gerência estatal, aproximando os órgãos públicos da realidade de empresas privadas e serviços públicos como fossem produtos, sempre com foco na máxima eficiência, racionalização de custos e nos resultados, aliados à finalidade de cada instituição pública. 


\section{Referências}

ALVIM, José Eduardo Carreira. Direito arbitral. 3. ed. Rio de Janeiro: Forense, 2007.

BRASIL. Constituição da República Federativa do Brasil, de 05 de outubro de 1988. Brasília, DF. 1988.

BRASIL. Lei no 5.869, de 11 de janeiro de 1973. Código de Processo Civil. Brasília, DF. 1973.

BRASIL. Lei no 7.783, de 28 de junho de 1989. Lei de Greve. Brasília, DF. 1989.

BRASIL. Lei $\mathbf{n}^{\mathbf{0}}$ 8.666, de 21 de junho de 1993. Lei de Licitações. Brasília, DF. 1993.

GASPARINI, Diógenes. Direito administrativo. 17. ed. São Paulo: Saraiva 2012.

MELO, Renato Alves de. Princípios Básicos que Regem As Licitações Públicas. JurisWay. Cajazeiras, 18 jun. 2010. Disponível em: < http://www.jurisway.org.br/v2/dhall.asp?id_dh=4234>. Acesso em: 29 fev. 2020.

MORAES, Alexandre de. Direito constitucional. 29. ed. São Paulo: Atlas, 2013.

PAGANO, Cláudio Miranda. A execução da sentença arbitral. Jus Navigandi, Teresina, ano 12, n. 1470, 11 jul. 2007. Disponível em: <http://jus.com.br/artigos/10136>. Acesso em: 29 fev. 2020.

$O(s)$ autor(es) se responsabiliza $(m)$ pelo conteúdo e opiniões expressos no presente artigo, além disso declara(m) que a pesquisa é original.

Recebido em 24/03/2020

Aprovado em 26/06/2020 